\title{
RR Interval Single Measurement
}

National Cancer Institute

\section{Source}

National Cancer Institute. RR Interval Single Measurement. NCI Thesaurus. Code

C117792.

An electrocardiographic measurement of the interval between two consecutive R waves.

If $\mathrm{R}$ waves are not present, this measurement may utilize the interval between the most easily identified components of the QRS complex within two consecutive beats. (CDISC) 